\title{
Vincenzo Neri: anatomy of a finding
}

\begin{abstract}
'Now try to imagine the young Neri who takes into the carriage his patients: they are hemiplegic, paraplegic, choreic, hysterical, senile dementia [...] try to imagine him carrying these pitiful specimens of humanity from the hospital to the studio of the photographer. It's a figurative representation between the fantastic and the demonic, between farce and tragedy, worthy of a Goya or a Daumier, even more than a Lautrec $[\ldots]^{\prime}$
\end{abstract}

Vincenzo Neri (1880-I96I) was an early twentieth century clinician who played a significant role in the history of clinical semiotics. Alongside direct visual observation, Neri experimented with three main methods to 'record' clinical signs in order to distinguish functional and psychiatric disorders from neurological diseases: the graphic method (footsteps impressions, drawings, diagrams); the chronophotographic method, and the photographic method. Neri was a pupil of Giuseppe Dagnini (1866-1928) in Bologna and Joseph Babinski (I857-I932) in Paris. From his first formative years and later as a clinician - first in Paris, from 1906-07, and then in Bologna as neurological consultant at the Rizzoli Orthopaedic Institute and as founder of the Villa Baruzziana clinic for nervous diseases - he attached great importance to neurological semiotics, observation and study of the manifestations and signs of disease.

Neri's studies were published in many journals, including some of the most prestigious, such as Revue Neurologique, Nouvelle Iconographie de la Salpêtrière. The signs and symptoms of diseases which he isolated and described were given his name in the neurological literature: the signs of Neri. The results of his research as well as the film frames and photographic images resulting from the clinical studies, were used and quoted by colleagues in important treaties of the time such as Sémiologie nerveuse, I9II. ${ }^{2}$

His first monograph, Le disbasie psichiche $e^{3}$ the result of studies and clinical research carried out between Paris and Bologna, dates from I9I0.4 Noteworthy is the interest of Neri in the relations between science and art, visual descriptions of diseases and the representation of the body in classical art. These relations are found in many documents and iconographic examples inside his archive. Today the Villa Baruzziana clinic is directed by Neri's nephew, who fortunately stored the original films and other astonishing visual materials dating from the early twentieth century. 


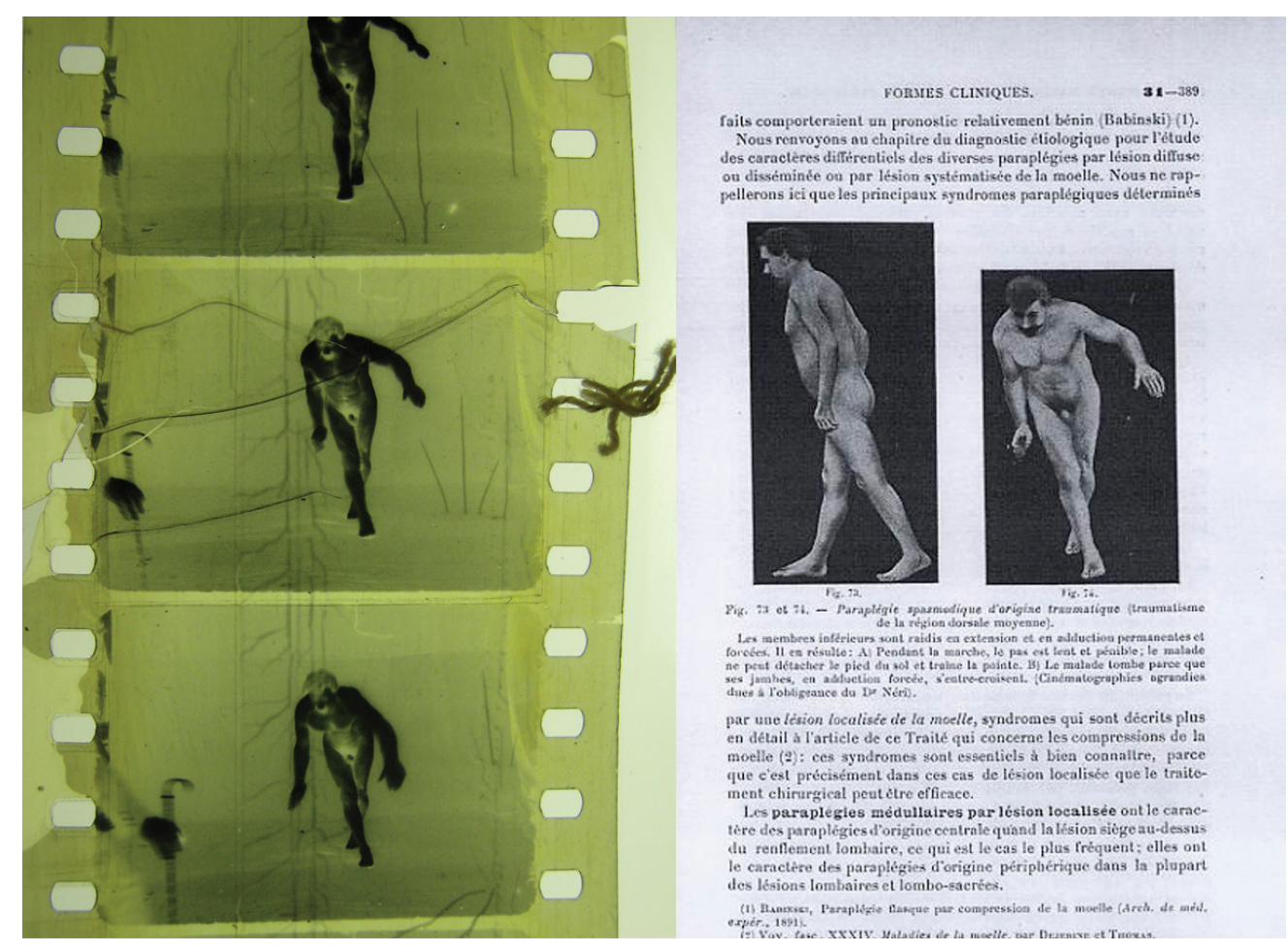

III. 1 Film- and photomaterial is used in publications. Source: from the archive of the Vincenzo Neri collection.

\section{The Collection and its Preservation ${ }^{5}$}

In 2008 the neurologist Lorenzo Lorusso rediscovered the Vincenzo Neri collection in Bologna. To demonstrate the relationship between the neurologists of the period and the dissemination of the scientific researches, Lorusso discovered the first traces about Neri and his interest in the use of film as scientific tool inside a necrology on Camillo Negro. ${ }^{6}$

The collection contains scientific visual material: 1572 artefacts, 1353 photographic elements (negatives, prints and photographic plates, as well as stereograms, reproductions of sketches of the imprint of the patients' feet); paper prints, audio recordings, indirect evidence (paper prints) of films in $17.5 \mathrm{~mm}$ (probably from a Biokam and dating back to I909-IO); II3 typographic stereotypes, cliché; 106 film artefacts $(35 \mathrm{~mm}$ camera negatives and projection positives, $16 \mathrm{~mm}$, 1907-1956 circa).

In addition to the medical films, the Neri Collection also shows us a large collection of other archival objects. These are traces of the scientific and epistemological framework, of the economy of the media and of the visual culture in the early twentieth century. The artefacts can be related to the scientific use of the cinematograph, but they can also be used to highlight the relationship between the cinema of attractions and the realm of gesture and visual culture. In other words they show the appearance of a new visual regime and a new semiotics of the body at the crossroads of science, ethics, aesthetics and bio-politics during the late nineteenth and early twentieth century. More generally, studying the entire Neri-collection, including this more complex set of documents, allows us to understand the framework in which the films were produced 
and the functions they performed.

In I907-1909 Neri started filming in Paris (patients from Bicêtre, Pitié, Salpêtrière). In particular the photographic and chrono-photographic method would accompany the whole trajectory of the professional life of Neri, finally constituting a large archive. Neri combined the semiotics of Babinski with the practice of Marey, working with rigour, constancy and originality. Apart from two edited elements dating from the end of the I940s, the film material is made up of unedited, separate elements.
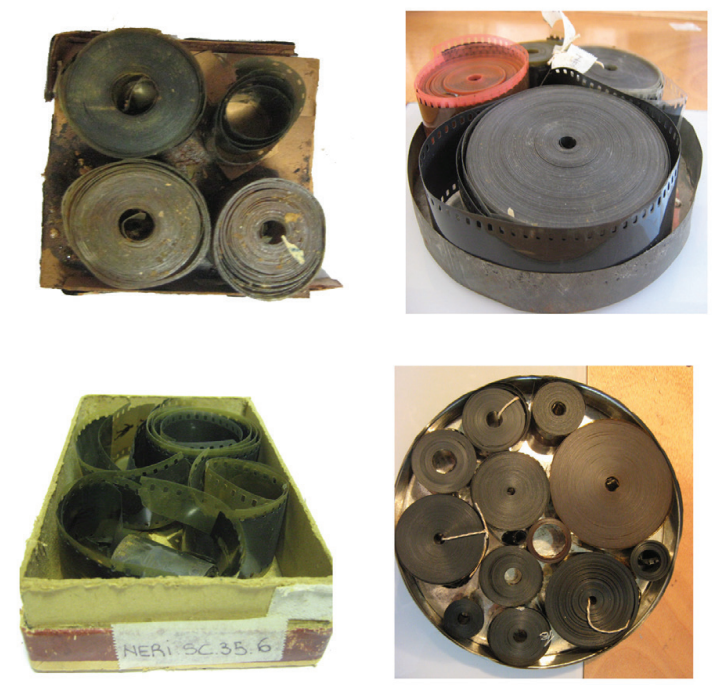

\section{2 Filmmaterial from the Vincenzo Neri collection}

Once its analytical function was completed, the film stock became part of an intermediality chain and an iconographic tradition. From the film to a paper print; from the paper print to a typographic cliché; from the cliché to a final image inserted in a table in a scientific publication. In the early twentieth century,- along with other visual media (print, photography) - film worked as a descriptive and analytical tool and as a communicative and didactical aid. Visual media objects such as slides, plates, and films, were useful for communicating other discourses such as science, and propaganda, but also served for archival purposes. As artefacts, they became an object of preservation in their time.

Following the Marey and Salpêtrière School's tradition, Vincenzo Neri used, renewed and revised graphic, film and photograph recordings for communication purposes and in order to create archives and reservoirs that innovate and consolidate a scientific and iconographic tradition. Le disbasie psichiche, Neri's first scientific publication, is a clear statement of the use of film and other contemporary media for scientific purposes. Also the shooting protocols explicitly came from the chrono-photographic practices and from the clinical protocols. In the preface of the Disbasie, Neri quotes the works and the teachings of Étienne-Jules Marey as fundamental for his work. Moreover, the shooting protocols should be linked with the tradition of the Salpêtrière school and in particular with Albert Londe, head of the photographic section of the Salpêtrière. 


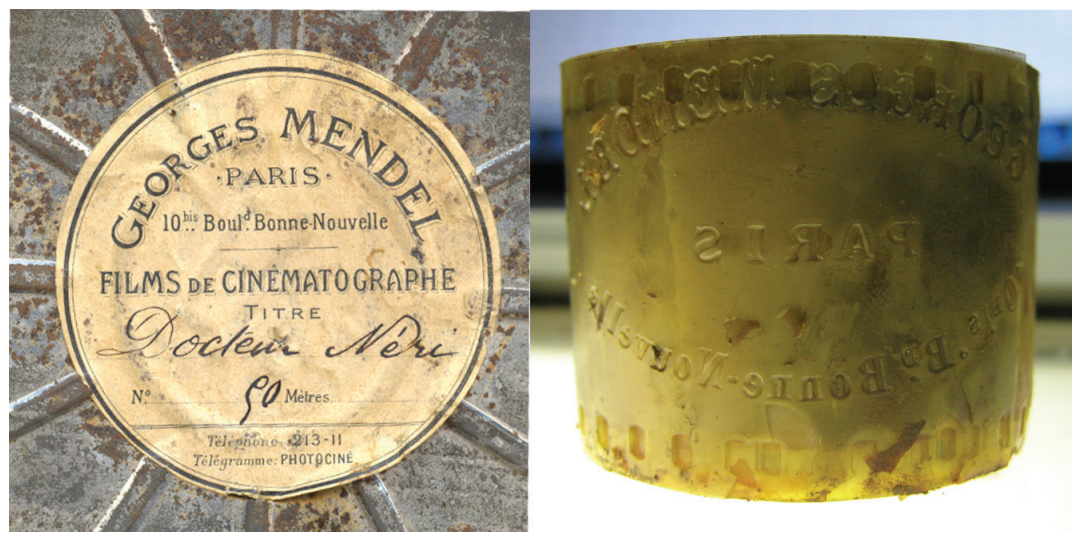

III. 3 Georges Mendel, Paris, Films de Cinématographe, 'Docteur Néri, go m.' From the Vincenzo Neri collection

The collection of $35 \mathrm{~mm}$ film (dating from I907 to 1928) was originally stored in fourteen cans and constituted by seventy archival units. Corresponding to the span of the period, there are materials in different forms and styles. The material, at least from the earliest period, consists of supports and emulsions produced at the margins of the early cinema industry and were shot and processed in an amateur way. From the beginning, the elements are from almost unknown origins; from the twenties they are familiar, Atrax-Tensi, Gevaert and Kodak for the negative and the tinted material. Considering the film prints, the result is a body of decomposing and fragmentary materials, which is very hard to reconstruct. The photo-chemical restoration - financed and carried out at the Haghefilm Laboratory of Amsterdam - has been part of a training programme sponsored by the Haghefilm Foundation, in the course of which the precarious material condition of a great part of the collection has been taken into account. The solutions found, to cope with the pronounced shrinkage and advanced state of decomposition of the materials, have enabled the recuperation of the collection far beyond our most optimistic expectations, guaranteeing the safeguarding of the complete and most representative sequences (sequences I-28).

The $2 \mathrm{~K}$ preservation of the $16 \mathrm{~mm}$ collection has been made at the La Camera Ottica Laboratory of the University of Udine, this research-lab based in Gorizia also recovered other $35 \mathrm{~mm}$ sequences. After the restoration in 2009, other sequences remained to be preserved, all dating back to 1908-1909 - the period Neri worked in Paris. The material, camera negatives on nitrate base, was in a highly critical condition, such as to prevent not only the use of hardware such as printers and film scanners but also their simple handling. In 2010 La Camera Ottica has developed and implemented a protocol for regeneration, scanning and digital restoration of this material. The recovered 9 sequences (numbered from number 29 to number 37), complete the preservation plan of the Neri Collection, in collaboration and with the support of Haghefilm, the Haghefilm Foundation and the Österreichisches Filmmuseum. The material is now accessible in its presumed chronological order: 37 sequences in all, numbered and separated by black frames.

As a final confirmation of our initial idea and purpose (the mapping and reconstruction of the neurologists' network operating in the early twentieth century), during the research and preservation project the Neri Group was able to 'discover' a collection of 'forgotten' Dutch scientific films, previously considered lost. The pioneer behind this collection was Gysbertus 
Godefriedus Johannes Rademaker.7 This finding started from a trace in the Neri collection: inside the collection we found a book by Rademaker containing film stills. ${ }^{8}$ Just another crossroad of the neurological network, the search continues.

\section{Notes}

I Guido Dagnini, Vincenzo Neri. Vita di Neurologo. "Bull. Scie. Med.”, 133, 1961, Bologna, p. 149-172.

2 Augustin Gilbert, Léon-Henri Thoinot, Sémiologie nerveuse, vol. xxxi, Librairie J-B Baillière et Fils, Paris 1911.

3 The Psychic Dysbasia, dysbasia means 'walking difficulties'.

4 Vincenzo Neri, Le disbasie psichiche, Tipografia Garagnani, Bologna 1910.

5 The research group for the Vincenzo Neri collection is a multi-disciplinary team composed of Lorenzo Lorusso (Department of Neurology, Chiara, Brescia), Karianne Fiorini, Paolo Simoni, Mirco Santi (Home Movies - Archivio Nazionale del Film, Bologna), Chiara Tartarini (Universita degli Studi di Bologna), Simone Venturini, Giulio Bursi, Claudio Domini, Giulia Barini, Federico Vanone (Università degli Studi di Udine - Laboratories La Camera Ottica and Crea, Udine/Gorizia), Alessandro Porro (Università degli Studi di Brescia) and Virgilio Tosi, Rome.

6 Lorusso realized the role of Neri thanks to an association of ideas during his firsts researches on the pioneers of italian scientific cinema as Negro and Polimanti. The research on Neri start from a reading of a necrology of Camillo Negro written by Gaetano Boschi that put in contact Negro and Neri: G. Boschi, 'Necrologie. Camillo Negro', in Giornale di Psichiatria clinica e tecnica manicomiale, vol. LV, I927, pp. 2I5-219. See p. 2I6: 'Fra molte rievocazioni personali e tristi e care: una sera di giugno, a Parigi, eravamo con Lui Vincenzo Neri ed io [...]'. [Among many personal and sad commemorations: A June evening, in Paris, we were with him, Vincenzo Neri and I (...)]. See also the text on the Negro collection by Stella Dagna and Claudia Gianetto in this dossier.

7 L.A.H. Hogenhuis, Cognition and Recognition: On the Origin of Movement: Rademaker (1887-1957). A Biography, Brill, Leiden 2009; L.A.H. Hogenhuis, Rademaker 1887-1957, in: J.A.M. Frederiks, G.W. Bruyn, P. Elin, History of Neurology in The Netherlands, Boom, Amsterdam 2002.

8 The Rademaker films are also discussed in this dossier. The films were preserved by the Nederlands Instituut voor Beeld en Geluid. The films have been identified in 2009-2011 thanks to the joint cooperation between the Neri Group (Lorenzo Lorusso, Simone Venturini) and the archivists of the collections stored in Scheveningen, Den Haag (Eva Hielscher, Amy Wensing, Patricia Gaetano), in collaboration with Bregt Lameris and Peter Koehler. 